\title{
EDUCAÇÃO MAKER: CONVERGÊNCIA DAS TECNOLOGIAS DE INFORMAÇÃO E COMUNICAÇÃO NA EDUCAÇÃO
}

\section{MAKER EDUCATION: CONVERGENCE OF INFORMATION AND COMMUNICATION TECHNOLOGIES IN EDUCATION}

\author{
Tatiana Soster ${ }^{1}$, Eliton Moura², Mariana Balaton³
}

\section{RESUMO}

O Movimento Maker tem despertado interesse na comunidade educacional, contribuindo para o crescente interesse pela implantação da educação maker nas instituições escolares do Brasil e do mundo. Desenvolvendo atividades educativas, ao mesmo tempo em que converge diversas Tecnologias de Informação e Comunicação, a educação maker propõe a condução de processos de prototipação, construção ou restauração de um produto, físico ou digital, relacionando tais processos a um conteúdo científico. Ela tem ocorrido, geralmente, embora não exclusivamente, em ambientes de fabricação digital, chamados espaços makers ou Fab Labs. Com o presente artigo, buscamos entender as bases históricas e teóricas que fundamentam a educação maker, bem como, o que essa metodologia pode significar para uma Sociedade 5.0. Neste percurso, apresentamos os principais conceitos que envolvem o tema, apontando direções para a atuação docente e a relação entre currículo e maker.

PALAVRAS-CHAVE: Educação Maker. Competências docentes. Formação de professores.

\section{ABSTRACT}

The Maker Movement has aroused interest in the educational community, contributing to the growing interest in implementing maker education in school institutions in Brazil and around the world. Developing educational activities, at the same time that various Information and Communication Technologies converge, maker education proposes the conduction of prototyping, construction or restoration processes of a physical or digital product, relating such processes to a scientific content. It has generally, though not exclusively, taken place in digital manufacturing environments called space makers or Fab Labs. With this article, we seek to understand the historical and theoretical bases that underlie maker education, as well as what this methodology can mean for a 5.0 Society. In this course, we present the main concepts that involve the theme, oriented towards the teaching performance and the relationship between the curriculum and the maker.

\section{KEYWORDS: Maker Education. Teaching skills. Teacher training}

\footnotetext{
${ }^{1}$ Doutora em Educação Currículo na linha de pesquisa de Novas Tecnologias na Educação pela PUC-SP com estágio na Graduate School of Education da Stanford University. Mestre em Administração de Empresas com ênfase em Administração, Análise e Tecnologia da Informação pela FGV-EAESP. Especialista em Gestão Empresarial (MBA) pela FGV-EBAPE. Bacharel em Informática pela PUCRS. Organizadora do livro Inovação Acadêmica e Aprendizagem Ativa do Consórcio STHEM Brasil. Experiência profissional nas áreas de educação, tecnologia e gestão. Atualmente é coordenadora e professora do curso de graduação em Administração Pública da FGV.

${ }^{2}$ Eliton Meireles de Moura é pesquisador do Transformative Learning Technologies Lab (TLTL) no Teachers College - Columbia University em Nova York. É Doutor em Educação pela Universidade de São Paulo (USP), com estágio de doutorado sanduíche na Universidade de Stanford, onde atuou como Visiting Student Researcher na Graduate School of Education, para o ano acadêmico de 2017-18. Licenciado em Matemática, possui ainda Mestrado em Educação na Linha de Pesquisa de Conhecimentos e Práticas Educacionais, ambas pela Universidade Federal de Uberlândia.

${ }^{3}$ Mestra em educação PUC-SP e em ensino de física e química na Universidade do Porto, pesquisadora sobre novas tecnologias para o ensino das ciências e metodologias ativas para ensino das ciências. A 10 anos é Professora de robótica e programação baseada em projetos para alunos do $2 .^{\circ}$ e $3 .^{\circ}$ ciclo do ensino básico.
} 


\section{INTRODUÇÃO}

O século XXI aparenta ser um dos mais desafiadores, especialmente em função da globalização da comunicação que permite sabermos em menos de um minuto fatos que aconteceram literalmente do outro lado do mundo. Para além das aparências, apresentando fatos reais, a mobilização de diversos países para trabalhar individual e colaborativamente na Agenda 2030 a fim de atingir os dezessete Objetivos para o Desenvolvimento Sustentável (ODS) aponta que realmente vivemos tempos desafiadores. Na Figura 1 são apresentados os 17 ODS:

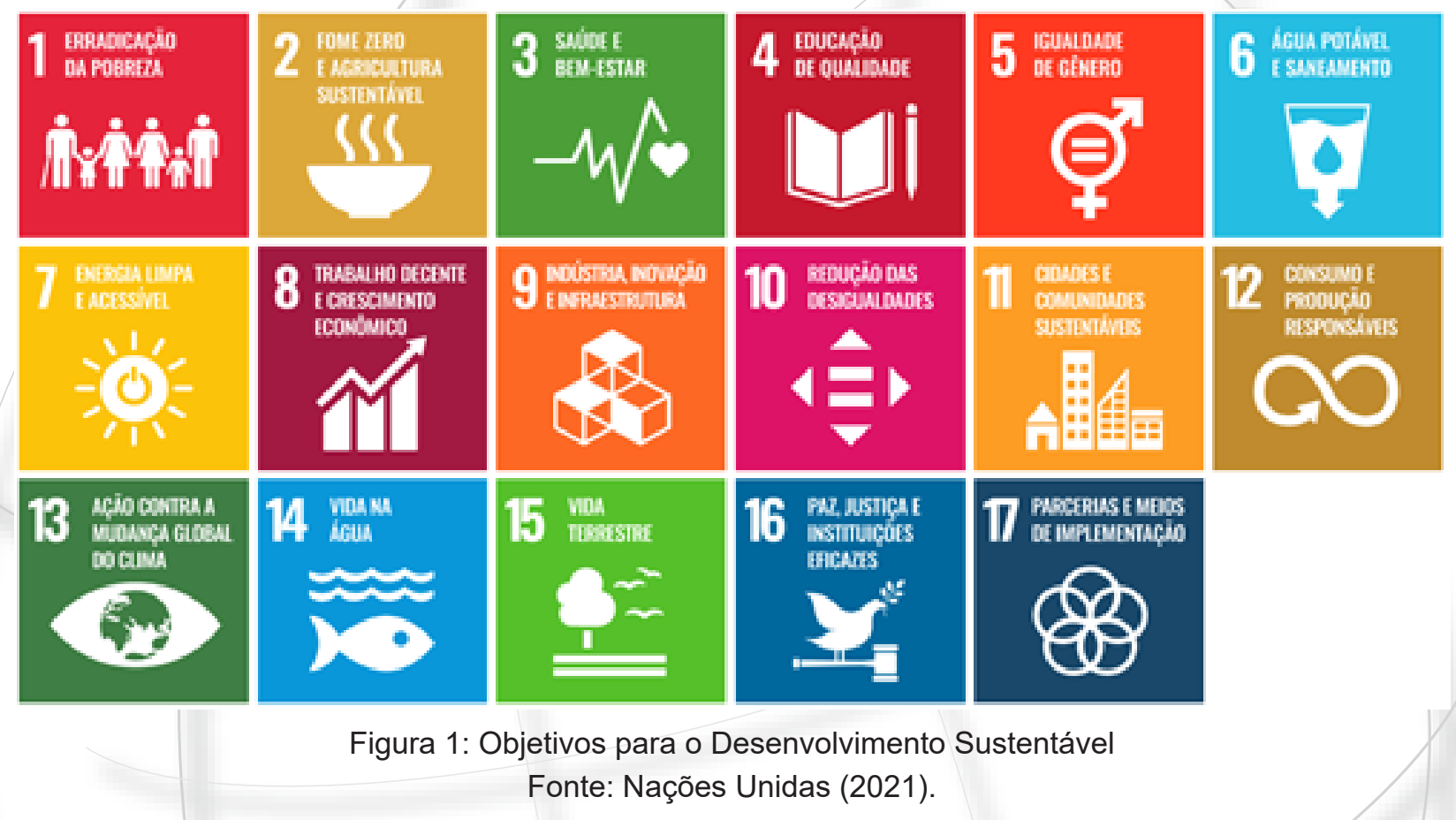

Os desafios globais como disparidade do crescimento econômico, esgotamento dos recursos naturais, intolerância à cultura ou à opinião diferente que leva aos extremismos e consequentemente à atos de violência contra o outro, entre outros, reafirmam que apesar dos enormes avanços da sociedade, ainda há muito o que ser resolvido.

Assim como a Agenda 2030 é uma proposta de projeto global, o conceito de Sociedade 5.0 propõe uma sociedade com uma visão comum de mundo que busca além de atingir os ODS, atender às necessidades dos diferentes grupos entregando a tão sonhada vida confortável, configurando-se como uma sociedade centrada no ser-humano. A sociedade 5.0 refere-se ao quinto estágio de desenvolvimento na sociedade humana, tendo sido construída em cima da sociedade 4.0 conhecida como a sociedade da informação.

A "sociedade super inteligente", como também é chamada a sociedade 5.0, propõe a integração do mundo físico (real) com o mundo digital (cibernético), através de cyber-physical systems (CPS) (HARAYAMA, 2017). Os sistemas cibernéticos combinam e se baseiam em elementos de diferentes teorias científicas e disciplinas de engenharia, incluindo cibernética, sistemas incorporados, controle distribuído, redes de sensores, teoria de controle e engenharia de sistemas. A Figura 2 apresenta a proposta da sociedade 5.0 para atender os ODS. 


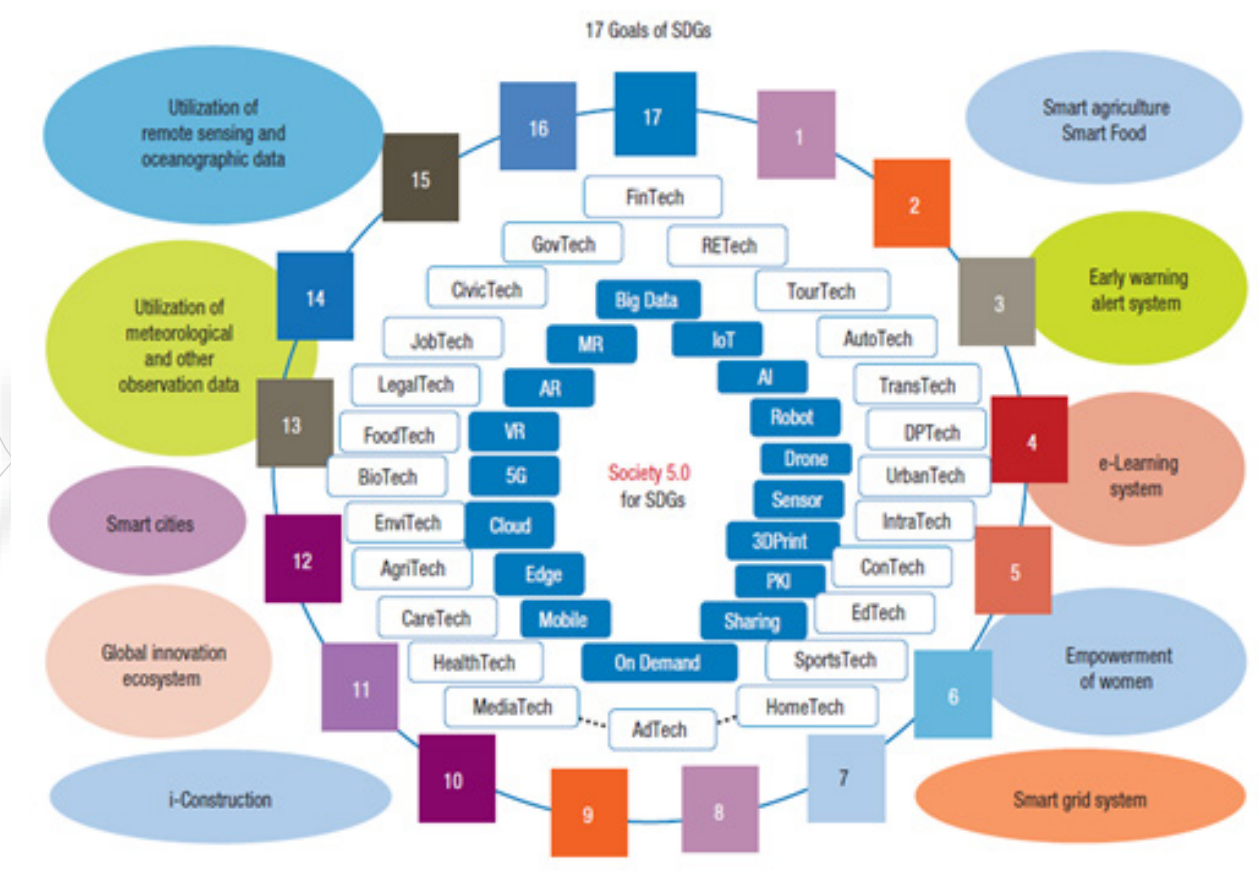

Figure 3. Society 5.0 for SDGs (Sustainable Development Goals). ${ }^{13}$

Figura 2: Sociedade 5.0 para ODS

Fonte: Shiroishi, Uchiyama e Suzuki (2018).

No centro da Imagem 2 são apresentadas as diferentes tecnologias (Big Data, loT, 5G, Cloud etc.) que são utilizadas pelos diversos segmentos da sociedade (governo, financeiro, educacional, saúde etc.) para atender aos 17 ODS através de sistemas que conectam o mundo físico com o digital.

O cenário apresentado faz parte da realidade global presente e futura. Novas tecnologias e sistemas dividem o mesmo espaço e tempo com antigos problemas e ultrapassados sistemas. Inteligência artificial para responder às necessidades humanas compartilha o mesmo espaço de sistemas políticos pós-coloniais disfarçados de democráticos. Automação inteligente no agronegócio que aumenta a produção de alimentos convive com pessoas ainda morrendo de fome e subnutrição. Diante desse cenário e preocupadas em responder às necessidades da Agenda 2030, a Organização para Cooperação e Desenvolvimento Econômico (OCDE) desenvolveu o conceito de competências globais e a UNESCO (Organização das Nações Unidas para Educação, Ciência e Cultura) desenvolveu o conceito de cidadania global, entendendo que todos os seres humanos devem desenvolver tais competências para a manutenção de um planeta sustentável.

Segundo OCDE (2018) a competência global é uma capacidade multidimensional na qual os indivíduos possuem a capacidade de examinar questões locais, globais e interculturais, entender e apreciar as diferentes perspectivas e visões do mundo, interagir de forma efetiva e respeitosa com os outros, e assumir a responsabilidade de agir para a sustentabilidade e para o bem-estar coletivo.

Já o conceito de cidadania global no contexto educacional tem como objetivo empoderar os aprendizes para assumir ativamente os seus papéis na construção de sociedades mais pacíficas, tolerantes, inclusivas e seguras (UNESCO, 2021). A proposta baseia-se em três domínios da aprendizagem:

- Cognitivo: conhecimento e habilidades de pensar necessárias para melhor compreender o mundo e suas complexidades.

- Socioemocional: valores, atitudes e habilidades sociais que permitem aos aprendizes desenvolverem-se afetivamente, psicossocialmente e fisicamente para conviverem com os outros de maneira respeitosa e pacífica. 
- Comportamental: conduta, desempenham aplicação prática e engajamento.

Ambas as organizações transnacionais acreditam que tais competências são suficientes para a transformação do mundo em um ecossistema sustentável, e advogam para que tais competências sejam desenvolvidas no contexto educacional global. Percebe-se que as duas propostas não trazem referência alguma sobre tecnologia, embora seja possível inferir que para conviver no mundo atual faz-se necessário não somente saber utilizar as tecnologias como também as produzir.

Inspirada em diversos estudos nacionais e internacionais, como por exemplo, no relatório sobre as competências globais para um mundo inclusivo e Agenda 2030 da Organização das Nações Unidas (ONU), o Brasil desenvolveu a Base Nacional Comum Curricular (BNCC) como uma resposta às demandas da sociedade para o século XXI. O documento é referência para a elaboração dos currículos nas escolas de educação básica estaduais e municipais. Embora a BNCC (2018, pg. 8) defenda que a "educação deve afirmar valores e estimular ações que contribuam para a transformação da sociedade, tornando-a mais humana, socialmente justa e, também, voltada para a preservação da natureza", muito pouca referência é apresentada na integração curricular com as tecnologias de informação e comunicação (TIC), aumentando a lacuna entre educação e tecnologia.

Atento a essa lacuna, o Centro de Inovação para a Educação Brasileira (CIEB) desenvolveu o Currículo de Tecnologia e Computação como uma opção para a implementação da BNCC inseridas no contexto das TIC. Embora a compreensão e utilização da proposta pareça simples, o país ainda carece de acesso de qualidade à internet para os estudantes nas escolas, especialmente nas escolas públicas (Cetic.br, 2019). Esse fato corrobora para o baixo desenvolvimento da literacia digital e computacional no âmbito da educação básica.

Embora os estudos citados até então não apresentem explicitamente as competências relacionadas à tecnologia, quando adentramos no mundo do trabalho, nota-se que a grande maioria das competências para o trabalho do presente e futuro envolvem o contexto tecnológico, conforme estudo realizado pelo Fórum Econômico Mundial (2020): pensamento analítico e inovação; aprendizado ativo e estratégias de aprendizagem; resolução de problemas complexos; pensamento crítico e análise; criatividade, originalidade e iniciativa; liderança e influência social; uso de tecnologia, monitoramento e controle; desenho (design) de tecnologia e programação; resiliência, tolerância ao stress e flexibilidade; raciocínio, resolução de problemas e ideação; inteligência emocional; solução de problemas e experiência do usuário; orientação ao serviço; análise a avaliação de sistemas; persuasão e negociação.

Cabe destacar nesse momento, que a educação brasileira está a serviço do desenvolvimento do educando para o exercício da cidadania e do trabalho (BRASIL, 1996), assim, é dever do Estado (e da família) e compromisso de as escolas formar indivíduos com as competências necessárias para o convívio sustentável na sociedade do século XXI, o que inclui a tecnologia dentro do currículo oficial.

Integrar todas as competências citadas acima não parece ser uma tarefa fácil. Por outro lado, ao longo do século passado, diversas práticas pedagógicas inovadoras foram desenvolvidas, mas até então pouco utilizadas no contexto da educação básica, como por exemplo, a aprendizagem baseada nas experiências (DEWEY, 1979), a aprendizagem com computador e micromundos (PAPERT, 1993), e a aprendizagem significativa-situada-emancipatória (FREIRE, 1976 e 1996). Tais propostas pedagógicas possuem o potencial de integrar as competências necessárias para o século XXI com as tecnologias vigentes e emergentes. É justamente no início do século XXI com o barateamento da tecnologia e consequente aumento ao acesso e na integração entre as pessoas a partir das redes sociais que surge a Educação Maker como uma proposta para formar os sujeitos com as competências necessárias para não somente responder à Agenda 2030, mas também capazes de entregar a tão sonhada vida confortável à humanidade.

\section{EDUCAÇÃO MAKER COMO UMA PROPOSTA PARA A SOCIEDADE 5.0}

A educação maker apresenta alguns pilares históricos que vieram consolidá-la hoje como uma proposta para desenvolver a Educação num cenário apresentado pela Sociedade 5.0. O Movimento Maker, fundamentando-se na cultura do "faça você mesmo", do inglês Do-it-Yourself (DIY), é um destes pilares. Este movimento traz duas 
importantes considerações, a primeira, por essência, é a ideia de que pessoas comuns podem construir, consertar, modificar e fabricar os mais diversos tipos de objetos e projetos (Moura, 2019, p. 39); segundo, coloca a colaboração e o compartilhamento como comportamentos fundamentais para os makers, como são chamados os integrantes do movimento que, amadores ou profissionais, atuam em diferentes áreas ligadas à ciência e à tecnologia, que se organizam com o objetivo de suportar mutuamente o desenvolvimento dos projetos uns dos outros. Percebe-se que, além de partilhar maquinário, o movimento reivindica uma identidade que se constrói a partir de valores voltados ao bem comum e ao prazer na transformação de objetos, adaptando-os a novos usos ou novas situações de uso.

Com o tempo, e a popularização da internet, os makers foram se encontrando, organizando e acabaram por criar um coletivo que reuniu adeptos em espaços físicos, capacitados com máquinas de fabricação digital, chamados espaços maker ou makerspaces, hackerspace, FabLabs, FabLearn labs, entre outras denominações. Estes espaços são outro importante pilar da educação maker. No começo da década de 2000, Neil Gershenfeld e colaboradores do Massachusetts Institute of Technology (MIT) criaram um espaço de fabricação digital de relativo baixo custo e passaram a levar o modelo para fora do campus. Nesses espaços, por meio do acesso a ferramentas de fabricação digital, os alunos estudavam as "fronteiras entre ciência da computação e ciência física" (GERSHENFELD, 2012, p. 46).

A educação maker tem outros pilares históricos - a Maker Faire e a MAKE Magazine, criadas nos EUA em 2006, popularizando as práticas DIY; o projeto FabLearn, que semeou comunidades de educadores maker e construiu os primeiros espaços em escolas em dezenas de países desde 2010 (MARTINEZ; STAGER, 2013). Para autores como Lallement (2015) e Eychenne e Neves (2013), as inovações trazidas neste movimento, com o avanço das comunicações propiciadas pela Web, podem desencadear um processo análogo ao que foi a revolução industrial no século XIX. Chris Anderson (2012), autor do livro Makers: a nova revolução industrial,vai além e aponta a cultura Maker como bandeirante da próxima revolução industrial, em que qualquer pessoa poderá fabricar seus produtos com um pouco de conhecimento em design, impressoras 3D, cortadoras a laser e robótica, ou mesmo pela democratização da programação de computadores e de plataformas de programação mais simples e baratas. Deste modo, a Cultura Maker se expandiu para comunidades, museus, bibliotecas, feiras de ciências e, por fim, alcançou as instituições de ensino.

Na Educação, a cultura maker ganhou espaço porque a própria ideia do "faça você mesmo" não é novidade na área. Educadores como Dewey (1916), Freinet (1998), Montessori (1965) e Freire (2008), antes, discutiram abordagens pedagógicas baseadas no "mão na massa". Já a pedagogia fundamentada nela, utilizando-se as tecnologias digitais, foi proposta por Papert e colaboradores (que cunharam o termo "construcionismo"), que se pauta pela ideia de que o conhecimento se realiza quando o aprendiz está engajado na produção de um objeto de seu interesse (PAPERT, 1986). As tecnologias digitais, especialmente os computadores, adquirem um papel de destaque porque "eles fornecem uma gama especialmente ampla de excelentes contextos para a aprendizagem construcionista" (PAPERT, 1991, p. 8). Portanto, segundo Blikstein, Valente e Moura (2020), a tradição intelectual do Construcionismo é outro pilar importante já que "preparou o terreno" teórico para que educadores maker construíssem uma compreensão mais profunda de suas próprias práticas.

De maneira simples, pode-se dizer que os educadores maker são aqueles que criam e desenvolvem toda e qualquer ação ou atividade, com viés educativo que, utilizando-se das Tecnologias, conduza um processo de prototipação/construção/manutenção de um produto ou serviço, físico ou digital, relacionando tal processo a um conteúdo científico (Moura, 2019, p. 25). Sua promoção é, geralmente, facilitada em ambientes de fabricação digital, tais como espaços makers, embora não exclusiva a estes locais. A integração do mundo físico com o mundo digital é exatamente a proposta supracitada pela Sociedade 5.0, corroborando para que a Educação Maker seja percebida como uma possibilidade para o desenvolvimento das competências para esta sociedade.

Não por acaso, pesquisadores perceberam que a aprendizagem baseada em metodologias construcionistas, como as oferecidas pelas atividades maker, podem propiciar as condições para que os aprendizes sejam criativos e críticos, bem como capazes de resolver problemas e trabalhar em grupo (MARTINEZ; STAGER, 2013; HALVERSON; SHERIDAN, 2014; KURTI; KURTI; FLEMMING, 2014; BLIKSTEIN; WORSLEY, 2016), competências essen- 
ciais para o século XXI.

Iniciar a transformação da cultura escolar tradicional para a cultura maker demanda a participação de todos os agentes da comunidade educacional. A seguir apresenta-se os elementos essenciais da educação maker para iniciar as discussões sobre tão almejada transformação educacional e consequentemente da sociedade.

\section{OS ELEMENTOS ESSENCIAIS DA EDUCAÇÃO MAKER}

Soster (2018) define a educação maker como:

O processo para guiar, instruir ou conduzir o educando para continuar sua própria educação com consciência da sua metacognição e visão crítica da sua situação atual, para transformá-la, caso desejado. Acontece em uma plataforma que estimula a expressão criativa na construção e compartilhamento de artefatos e produções intelectuais, através da promoção do desenvolvimento da autonomia, da identidade Maker, de conhecimentos poderosos e de habilidades em ferramentas, tecnologias, práticas e processos do contexto Maker, e demais áreas de conhecimento, de maneira integrada. (SOSTER, 2018, p.152).

Tal definição apresenta a Educação maker como um processo, algo contínuo, fluido, que não tem fim definido, ao mesmo tempo que o seu objetivo é claro: formar pessoas capazes de continuar a sua própria formação através da conscientização do seu processo de aprendizagem e visão crítica para tomada de decisão no sentido de optar por se manter na trajetória já percorrida ou direcioná-la considerando o espectro existente entre o contexto micro e macro, ou seja, dentro do seu processo de aprendizagem, de como se comportar no mundo, até efetivamente transformar sua residência, bairro, cidade, estado, país, e por que não o planeta?

A definição também posta a premissa do ambiente no qual a educação maker pode acontecer identificando como uma plataforma (física ou digital) que estimula a criatividade e o compartilhamento das produções dos estudantes. Soster (2018) acrescenta características essenciais ao ambiente maker, tais como: respeitoso (os estudantes podem se expressar livremente, sem medo de julgamentos), inclusivo (aceita seres humanos independentemente de suas características individuais), colaborativo, flexível, LFHCWW ${ }^{4}$, considera os ambientes físico e digital, aberto à comunidade, não restrito ao espaço, ou seja, extrapola o espaço para instalar-se como parte da cultura educacional.

Nos ambientes makers os recursos estão disponíveis e acessíveis aos estudantes, incluindo recursos para fabricação, computação física, programação, materiais diversos e recursos especialmente desenvolvidos para o contexto educacional como micromundos e os próprios projetos dos estudantes, conforme pode ser verificado na Imagem 3. A tecnologia é entendida como material de construção, ferramenta de expressão e deve ser desenvolvida considerando a proposta de Resnick (2017) adaptada de Papert (1993) cujo acrônimo LFHCWW já foi explicado anteriormente nesse artigo. $\mathrm{O}$ acesso e uso da internet faz parte do dia a dia dos ambientes makers, pois a internet é considerada fonte de informação e instrução a partir da curadoria dos professores.

\footnotetext{
${ }^{4}$ O acrônimo LFHCWW (Low Floor, High Ceiling and Wide Walls, em português: piso baixo, teto alto, paredes largas) foi criado por Papert (1993) e adaptado por Resnick (2017).
} 


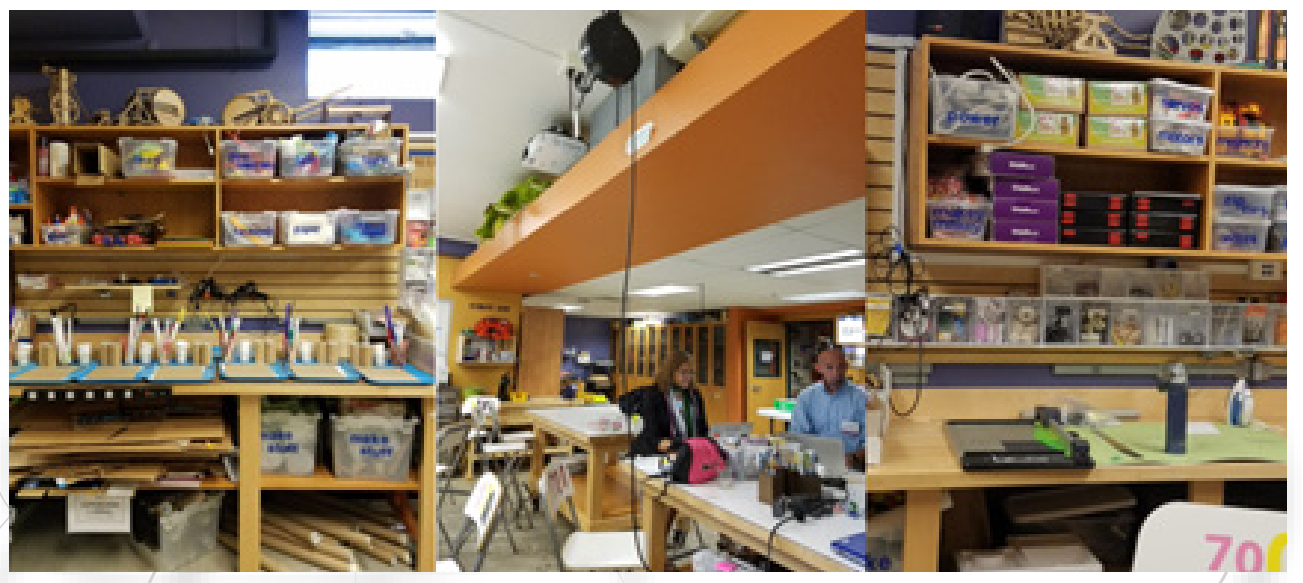

Imagem 3: Exemplos de espaços maker em escolas

Fonte: Vista à Castilleja Bourn Idea Lab5 2017.

Outro elemento essencial da educação maker é o conhecimento. Considerando as competências para o século $\mathrm{XXI}$ e as propostas pedagógicas centradas no estudante faz-se necessário incluir no currículo a literacia computacional e o pluralismo epistemológico, compreendido como a validade de múltiplas formas de conhecer e pensar (TURKLE; PAPERT, 1991). Por fim, é ingenuidade (ou até ignorância) acreditar que é possível incluir infinitamente conhecimentos e competências na BNCC e nos seus desdobramentos considerando a restrição de tempo (período da educação básica) e espaço (escola). Diante do exposto, outra característica do conhecimento no contexto da educação maker é a priorização pela seleção de conhecimentos poderosos, ou seja, dos conhecimentos realmente necessários para a construção e manutenção de uma sociedade sustentável.

A articulação do espaço com os recursos disponíveis para o desenvolvimento de competências e novos conhecimentos no estudante acontece através do processo de ensino-aprendizagem. A partir dos estudos das teorias e práticas da educação maker, Soster (2018) descreve a essência do processo de ensino-aprendizagem:

Parte do pressuposto que os alunos aprendem fazendo, construindo (interagindo com materiais, ferramentas e equipamentos), compartilhando, ensinando, documentando e principalmente refletindo sobre seu processo de aprendizagem (metacognição); sendo assim, considera que os atos de experimentar, explorar, prototipar e fabricar fazem parte do processo; é personalizado partindo da curiosidade e paixão do educando; respeita os diferentes estilos de aprendizagem, o tempo de cada aluno, e aceita as múltiplas maneiras de pensar e construir o conhecimento; presta atenção ao equilíbrio dos quesitos frustração, zona de conforto e tentativa-erro ("não se pode acertar sem errar"); utiliza a abordagem interdisciplinar, de projetos e resolução de problemas combinando atividades mão-na-massa e de reflexão (hands-on/head-in); estimula o auto aprendizado através de fontes diversas e a autogestão com apoio do educador; promove a criatividade, a colaboração e a parceria de forma flexível com colegas, professores, especialistas e comunidade; encoraja a autonomia no aluno e a construção da identidade Maker. (SOSTER, 2019, p.56).

O que o processo descrito traz de novidade é a convergência de diversas práticas pedagógicas ativas e materiais variados (computador, impressora a laser, papel, tesoura, cola quente etc.) para promoção do desenvolvimento de competências e conhecimentos através da resolução de problemas de interesse do estudante, entendendo que o colega e/ou o professor tem o potencial de produzir uma solução mais efetiva. Ultrapassando os muros da escola, esse é o processo metacognitivo e social almejado para a sociedade 5.0.

A avaliação faz parte do processo de ensino-aprendizagem e considera que todo o processo deve ser avaliado a partir de evidências e não somente o produto final. Nesse contexto, a avaliação considera as perspectivas cogniti-

${ }^{5}$ Castilleja Bourn Idea Lab - https://www.castilleja.org/learning/experiential-learning/maker-spaces 
va, emocional e motora, afinal, os estudantes constroem algo tangível e de forma colaborativa. Para facilitar a avaliação do processo, as pesquisas no contexto da educação maker recomendam o uso de rubricas para apresentar os critérios para o desenvolvimento dos projetos, normalmente no início da atividade, checklists, testes, autoavaliação, avaliação por pares e especialistas (SOSTER, 2018; SOSTER, FUHRMANN, CAMPOS, 2020).

O Quadro 1 apresenta as características essenciais dos principais atores da educação maker:

Quadro 1: Características essenciais dos principais atores da educação maker.

\begin{tabular}{|c|c|}
\hline Estudante & Professor \\
\hline $\begin{array}{l}\text { Eterno aprendiz, crítico, criativo, colaborativo, e } \\
\text { responsável pelo seu processo de } \\
\text { aprendizagem e desenvolvimento da } \\
\text { autonomia; aprende a partir da interação com } \\
\text { seus projetos, na busca de soluções para os } \\
\text { problemas, através do engajamento em várias } \\
\text { atividades, desenvolvendo habilidades e } \\
\text { conhecimentos, e compartilhando-os; se } \\
\text { movimenta pelo espaço explorando os recursos } \\
\text { para construir seus artefatos, registrando e } \\
\text { refletindo sobre seus experimentos; tem perfil } \\
\text { de fazedor, explorador e engenheiro; pensa } \\
\text { como cientista e compartilha suas descobertas } \\
\text { como contador de histórias. }\end{array}$ & $\begin{array}{l}\text { Eterno aprendiz, inspirando o alunado a partir de } \\
\text { suas atitudes de cientista do aprendizado; segue o } \\
\text { lema "fazer para nós mesmos o que fizermos para } \\
\text { os alunos"; desenvolve atividades que encorajam } \\
\text { a coinspiração, cocrítica, a autonomia, empatia e a } \\
\text { responsabilidade nos alunos; estimula os } \\
\text { educandos a compartilharem seus conhecimentos } \\
\text { e habilidades; é refratário à visão de autoridade do } \\
\text { conhecimento, redirecionando a autoridade para } \\
\text { especialistas, recursos online, técnicos etc. } \\
\text { (quando for o caso); tem perfil de explorador e } \\
\text { aprendiz das novas tecnologias, ferramentas e } \\
\text { utilização de materiais; está sempre se } \\
\text { movimentando pelo espaço de aprendizagem e } \\
\text { realiza intervenções curtas, relevantes e suficiente } \\
\text { para dar espaço ao desenvolvimento do educando } \\
\text { - "menos nós, mais eles"; fornece comentários ou } \\
\text { questionamentos quando necessário para } \\
\text { estimular o progresso do educando em seu projeto; } \\
\text { provedor de um espaço seguro física e } \\
\text { emocionalmente para que o educando se } \\
\text { experimente como cientista, inventor, explorador e } \\
\text { protagonista do seu processo de aprendizagem; } \\
\text { trabalha em rede, local ou mundialmente. }\end{array}$ \\
\hline
\end{tabular}

Fonte: elaborado pelos autores inspirado em Soster (2018, p. 156-158)

Para que as experiências educacionais neste processo desenvolvido em espaços makers ocorram de maneira eficaz, é necessária, como apontado no quadro, uma nova conduta do trabalho docente e das competências dos professores, provocando, por sua vez, um repensar sobre a formação docente, abrangendo um ensino criativo e significativo do currículo. Na busca por refletir sobre uma Formação Docente que promova o desenvolvimento de competências para o trabalho com a educação maker, iremos buscar em Moura (2019) a discussão e concepção sobre um processo formativo docente e maker.

\section{A FORMAÇÃO DO PROFESSOR PARA A EDUCAÇÃO MAKER}

Na busca por refletir sobre o impacto das novas tecnologias no trabalho docente, Kenski (1998) faz uma reflexão profunda sobre as novas formas de ensinar e aprender. Seguindo esta lógica de pensamento, Kenski (1998) esclareceu que:

Favoráveis ou não, é chegado o momento em que nós, profissionais da educação, que temos o conhecimento e a informação como nossas matérias-primas, enfrentarmos os desafios oriundos das novas tecnologias. Esses enfrentamentos não significam a adesão incondicional ou a oposi- 
ção radical ao ambiente eletrônico, mas, ao contrário, significam criticamente conhecê-los para saber de suas vantagens e desvantagens, de seus riscos e possibilidades, para transformá-los em ferramentas e parceiros em alguns momentos e dispensá-los em outros instantes (KENSKI, 1998, p. 61).

Não se trata de afirmar que a presença das tecnologias na sociedade, por si só, justifica sua integração à educação, mas de considerar que o aluno nascido na era digital (PALFREY, 2011) tem um perfil diferenciado e aprende a partir do meio social e cultural em que vive fora da escola (OLIVEIRA, 2003), no qual estão presentes as tecnologias.

Assim, não se pode pensar em utilizar a qualquer custo as tecnologias, mas, sim, acompanhar consciente e deliberadamente uma mudança de civilização que está questionando profundamente as formas institucionais, as mentalidades e a cultura dos sistemas educativos tradicionais e, notadamente, os papéis de professor e aluno (LÉVY, 1999, p.08).

Segundo Oliveira (2007), é necessário compreender as contribuições e dificuldades da inclusão de ferramentas tecnológicas na prática pedagógica. No início dos debates sobre introdução dos computadores na escola, professores mostravam resistência à introdução desta nova ferramenta no ensino porque pensavam que, assim como em outros ramos de atividade, seriam substituídos por essas máquinas (CARNEIRO; PASSOS, 2006).

A partir do entendimento cada vez mais esclarecido das potencialidades do computador, que ganhava cada vez mais adeptos na sociedade, consequentemente nas escolas, é que foi sendo desconstruída a ideia de que o professor teria seu lugar "roubado" pelas máquinas, mas, sim, que teria um importante papel na condução desse novo artifício para a educação. Iniciava-se a revisão da atuação do professor no contexto escolar, bem como sua formação e sua prática pedagógica para desenvolver sua docência, transformando-se em agente de mudança, também num contexto tecnológico. Para o professor se sentir confiante no uso das tecnologias e vencer o sentimento defensivo em relação a elas, que ora percebe como ameaça, ora como concorrente, ao invés de aliadas (TEDESCO, 1998; KENSKI, 2003), não bastam saberes instrumentais do tipo noções de Informática.

Mercado (2002) ainda afirmava que "não basta colocarmos a disposição só o computador, é preciso preparar este professor, respeitar o seu tempo e fazer com que ele entenda o porquê de uma nova ferramenta de trabalho" (p.32). Este aspecto adquire relevância na perspectiva de Veiga (2003), para quem as inovações não terão chance de sucesso, se os atores não as aceitarem e não se envolverem em sua própria construção, perspectiva que vem ao encontro do que afirmam Sandholtz, Ringstaff e Dwyer (1997).

A partir desse início, houve nas licenciaturas a presença constante do desafio de se formar o docente com as tecnologias. Uma boa oportunidade inclusive para, no movimento de se reinventar social e politicamente, ter na própria tecnologia, um potencial aliada neste sentido. Porém, existe uma ironia na formação de professores envolvendo tecnologia. Já vimos neste artigo, na Introdução, que ao invés de mergulhar neste universo, seguindo o movimento da sociedade, a licenciatura continua mantendo as tecnologias de maneira muito tímida, recebendo pouco destaque na formação de professores.

São poucas disciplinas que tentam integrar as tecnologias na formação do futuro docente. Ao tratarem sobre tecnologia, a consideram apenas em relação ao que os estudantes da educação básica precisam. Como resultado, podem negligenciar aos professores um aprendizado tecnológico significativo, embora esperem deles ações que apoiem seus alunos com tecnologia.

Outras vezes, mesmo oferecendo uma formação tecnológica voltada para seu desenvolvimento e protagonismo, as licenciaturas acabam por não conseguir proporcionar um ambiente de aprendizado ideal ou oferecer aos professores todas as ferramentas de que precisam para ter sucesso, incluindo uma das ferramentas mais essenciais na tecnologia - o tempo de interação. Assim como os estudantes do ensino básico, e qualquer pessoa, os futuros professores precisam de tempo para absorver novos conceitos e precisam ter acesso ao apoio contínuo para implementar as estratégias instrucionais que obtêm da formação.

Sabemos que as dificuldades e desafios sobre a formação de professores são muito mais complexos que essas duas questões que aqui brevemente abordamos, mas, mesmo apesar dos dilemas na profissão docente e do 
drama vivido no cenário de abandono da formação de professores, contraditoriamente as licenciaturas se constituíram em um espaço de luta que abriu caminho para o magistério ser reconhecido como profissão, na qual o professor pode refletir sobre o ato educativo e preparar-se para romper com os mecanismos que desfiguram o seu o ofício.

Formar um professor é um desafio diário e necessário, por isso é tão importante pensar continuamente as estruturas de sua própria formação, afinal, tomando como premissas norteadoras a "inconclusão do ser humano", o engajamento político e o compromisso ético, Freire (1996, p.14) tece argumentos "sobre a prática educativo-progressista em favor da autonomia do ser educando". Prática essa que só se viabiliza com uma formação docente que seja coerente com a formação integral do ser humano.

Moura (2019), em estudo recente, enunciou 5 Competências necessárias à prática educativa e maker, apoiado nos estudos de Papert (1999), Freire (2001), Blikstein (2013), Resnick (2016), Valente (2019), Perrenoud (2000) e levando em conta ainda os Princípios Maker (1999). São elas:

1. Ensinar aprendendo e aprender fazendo, bancando a Rigorosidade Metódica na construção do conhecimento e envolta em um contexto problematizador real e significativo;

2. Letrar-se em Tecnologia, humanizando-a como material de construção de conhecimento e fomentando-a como direito do educando;

3. Planejar o Tempo, permitindo a segurança, o encantamento, a motivação, o erro, a mudança, a autonomia, e o pensamento crítico-reflexivo;

4. Relacionar-se dialogicamente na liberdade, na autoridade e no respeito, valorizando o conhecimento do outro e compartilhando com parcerias;

5. Formar-se permanentemente num projeto reflexivo e progressista de amorosidade e de compromisso de transformar realidades, formando e valorizando sujeitos críticos e sonhadores.

Na prática, o professor deve saber equilibrar o currículo educacional com os princípios maker. O currículo não deve ser definido a priori e imposto, mas é baseado na intencionalidade pedagógica do professor, reconstruída pelas ações dos alunos e do professor.

As atividades a serem desenvolvidas nos espaços maker devem ser pensadas como atos de currículo de modo que a aprendizagem, a negociação de significados e a atribuição de sentido tenham origem na interação social com as pessoas, com os materiais e com as tecnologias presentes nesses espaços.

Para que a educação maker possa dar suporte aos atos de currículo e à interdisciplinaridade, é importante que a integração das atividades maker ao currículo das disciplinas seja realizada de forma fundamentada e não como modismo. Primeiro, a tecnologia deve ter uma função de auxiliar a realização de algo que não pode ser feito adotando métodos convencionais. Segundo, é necessário nivelar a tecnologia à proposta educativa, ou seja, não é sensato utilizar vários equipamentos tecnológicos para abordar um conteúdo que não os demanda. (BLIKSTEIN, VALENTE e MOURA, 2020. p. 529)

A Figura 3 ilustra o balanço que deve guiar a criação de atividades educacionais maker: de um lado, o currículo, que para ser colocado em prática envolve a formação do professor, o desenvolvimento científico e o conhecimento a ser trabalhado; de outro, o trabalho maker, envolvendo criação, desenvolvimento tecnológico e o mundo real. A metáfora da balança indica que esses dois componentes devem estar em equilíbrio - não pender para o lado do currículo, nem para as práticas maker. 

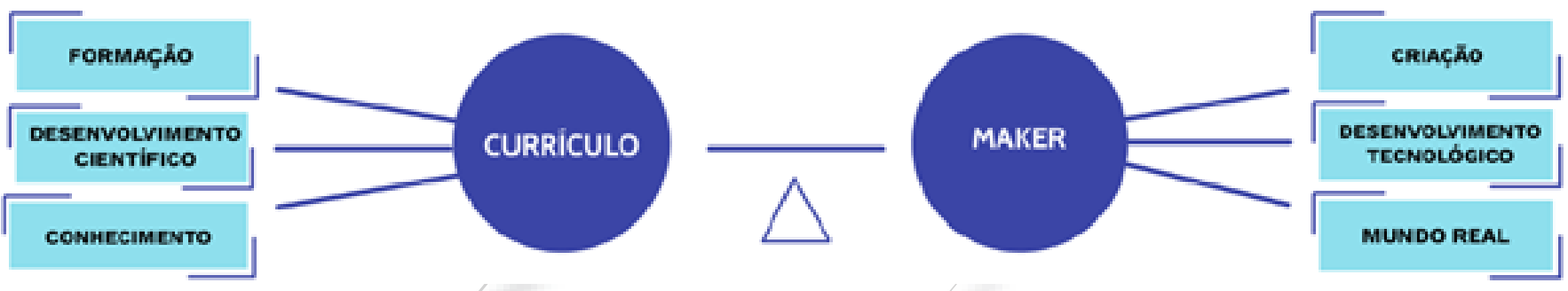

Figura 3 - Balança entre Currículo e Maker. Fonte: Blikstein, Valente e Moura (2020)

Equilibrar essa balança significa considerar a formação e a criatividade do aluno, fazendo um exercício de olhar para a sua própria formação e criatividade, desenvolvendo ao mesmo tempo aspectos científicos e tecnológicos.

\section{CONSIDERAÇÕES FINAIS}

Esse artigo buscou apresentar uma proposta educacional que contempla as necessidades de competências para o século XXI: a educação maker. Entendo que o professor é peça fundamentar dessa proposta, o estudo buscou repensar a atuação docente sob uma práxis transformadora, abrangendo um ensino criativo e significativo do currículo, na utilização pedagógica de elementos tecnológicos contemporâneos, que têm na educação maker, hoje, dos mais completos cardápios neste sentido, já que esta tem uma perspectiva de convergência de mídias.

Neste sentido, discutimos a reformulação de uma Formação de Professores corroborando para a utilização pedagógica de elementos tecnológicos contemporâneos no desenvolvimento de uma práxis transformadora. Resumidamente, listamos os principais apontamentos:

- Estimular a rigorosidade metódica como diversão difícil, adotando o pensamento crítico e a criação como exercício permanente;

- Utilizar a pesquisa como possibilidade de registro e produção de atividades pedagógicas contemporâneas, tecnologicamente;

- Buscar espaços físicos subutilizados ou ociosos para instalação de espaços makers, perseguindo a aquisição de equipamentos tecnológicos diversos e envolvendo os alunos da licenciatura nas operações de manutenção dos espaços e dos equipamentos;

- Ofertar disciplinas com tecnologia durante todo o curso, permitindo ao licenciando a possibilidade de criar seu material didático adaptando conceitos e considerando as necessidades e recursos locais.

- Ter consciência e procurar solucionar as limitações, iniciais, sobre o Tempo e o Espaço, das quais se incluem: tempo restrito da aula; equipamentos do espaço maker em manutenção; pouco conhecimento técnico dos professores das universidades; dentre outros.

- Aprender a lidar com as novas relações interpessoais, que podem ser criadas na adição da figura do Técnico Maker;

- Fomentar a criação e manutenção de redes de colaboração e apoio, um ecossistema educativo, envolvendo as Escolas, a Sociedade e seus diversos aparelhos institucionais (Fab Labs, museu, praças), e a própria universidade.

Como resultado deste estudo, vimos que os professores têm pouco e precariamente conduzido atividades maker em sua prática, e, quando o fazem, raramente relacionam tal processo ao currículo escolar. Tal conduta acaba por reforçar a cultural distância existente entre a escola e as tecnologias, porém, não há como responsabilizar apenas o professor por tal cenário, já que esta pesquisa também verificou que as formações pouco têm preparado o docente para uma prática com tecnologias.

Percebemos ainda que, ao habitar um universo de contenção, no que diz respeito ao controle que rege sobre os alunos, a escola, por julgar conhecer todas as etapas necessárias a seu aprendizado, acaba por inibir quase que completamente a possibilidade de autoria dos estudantes. Devido a esse modelo de educação, não é difícil se de- 
parar com jovens e adultos com pouca iniciativa, meros reprodutores e com dificuldade de integração e cooperação, abatidos numa sociedade que exige perante as inúmeras transformações sociais, sobretudo de cunho tecnológico, um perfil de cidadão ativo, participante, interativo, informado, e interligado com o mundo.

A escola precisa, por isso, firmar-se como local privilegiado, embora não único, para uma aprendizagem libertadora e o uso crítico das tecnologias. Assim, a pesquisa buscou inspiração nas experiências educacionais no processo de produção com tecnologia, desenvolvidas em espaços makers que, de fato, têm exigido uma nova conduta do trabalho docente e das competências do professor, criando possibilidades de reinventar modos de educação mais humanizados, compartilhados e integrais, à medida que busca-se o desenvolvimento, com as tecnologias, de ações educativas numa perspectiva dialógica, emancipadora, participativa, criativa e compartilhada, que contribua para a autonomia dos envolvidos no que diz respeito à sua condição de autores de sua trajetória.

\section{REFERÊNCIAS}

ANDERSON, C. Makers A nova revolução industrial. Elsevier Editora, 2012.

BLIKSTEIN, Paulo; WORSLEY, Marcelo. Children are not hackers: building a culture of powerful ideas, deep learning, and equity in the Maker Movement. In: PEPPLER, Kylie; HALVERSON, Erica R.; KAFAl, Yasmin B. (Eds.). Makeology: makerspaces as learning environments. New York: Routledge, v. 1, p. 64-79. 2016.

BLIKSTEIN, Paulo; VALENTE, Jose; MOURA, Éliton Meireles. Educação maker: onde está o currículo? Revista e-curriculum, v. 18, n. 2, p. 523-544. 2020.

BNCC - Base Nacional Comum Curricular $(2015 ; 2018)$. MEC/SEB. Brasil. Disponível em: <http://basenacionalcomum.mec.gov.br/> e <http://basenacionalcomum.mec.gov.br/images/BNCC_El_EF_110518_versaofinal_site.pdf>. Acessado em: mar. 2021.

BRASIL. MEC. Lei no. 9.394, de 20 de dezembro de 1996. Estabelece as diretrizes e bases da educação nacional. Diário Oficial da União, Brasília, DF, 23 dez. 1996. Disponível em: <http://www.planalto.gov.br/ccivil_03/Leis/L9394. htm>. Acesso em: 29 jan. 2018.

CARNEIRO, R. F; PASSOS, C. L. B. Formação Inicial e Tecnologias da Informação e Comunicação: Implicações na Prática Docente de Professores de Matemática em Início de Carreira. EBRAPEM. Belo Horizonte: MG, 2006.

CETIC.BR. Pesquisa sobre o uso das Tecnologias de Informação e Comunicação nas escolas brasileiras TIC Educação 2019. Disponível em < https://cetic.br/pt/publicacao/pesquisa-sobre-o-uso-das-tecnologias-de-informacao-e-comunicacao-nas-escolas-brasileiras-tic-educacao-2019/>. Acesso em: 31 mar. 2021.

DEWEY, John. Democracy and education. New York: The Free Press, 1916.

DEWEY, John. Experiência e Educação. 3. ed. São Paulo: Companhia Editora Nacional, 1979.

EYCHENNE, F.; NEVES, H. Fab Lab: A Vanguarda da Nova Revolução Industrial. São Paulo: Editorial Fab Lab Brasil, 2013.

FÓRUM ECONÔMICO MUNDIAL. The Future of Jobs Report 2020. Disponível em <https://www.weforum.org/ agenda/2020/10/top-10-work-skills-of-tomorrow-how-long-it-takes-to-learn-them/>. Acesso em: 26 jun. 2021. 
FREIRE, Paulo. Pedagogia da Autonomia: saberes necessários à prática educativa. São Paulo: Paz e Terra, 1996.

FREIRE, Paulo. Educação como prática da liberdade. 6. ed. São Paulo: Paz e Terra, 1976.

FREINET, Célestin. Educação pelo trabalho. São Paulo: Martins Fontes, 1998.

FREIRE, Paulo. Pedagogia da autonomia: saberes necessários à prática educativa. São Paulo: Paz e Terra, 2008.

GALEANO, Eduardo H. Las palabras andantes. Siglo XXI, 1993.

GERSHENFELD, Neil. How to make almost anything: the digital fabrication revolution. Foreign Affairs, v. 91 , n. 6 , p. 43-57, 2012.

HALVERSON, Erica R.; SHERIDAN, Kimberly M. The maker movement in education. Harvard Educational Review, Cambridge, v. 84, n. 4, p. 495-504, 2014.

HARAYAMA, Yuko. "Society 5.0: Aiming for a New Human-Centered Society." Hitachi Rev., v. 66, n. 6, pp.556-557, 2017. Disponível em <http://www.hitachi.com/rev/archive/2017/r2017_06/pdf/p08-13_TRENDS.pdf>. Acesso em: 05 abr. 2021.

KENSKI, Vani Moreira. Novas tecnologias - o redimensionamento do espaço e do tempo e os impactos no trabalho docente. Revista Brasileira de Educação, Rio de Janeiro, n. 8, p. 58-71, maio./ago. 1998.

KENSKI, Vani Moreira. Novas tecnologias na educação presencial e a distância I. In: BARBOSA, R. L. L. (Org.). Formação de educadores: desafios e perspectivas. São Paulo: Editora UNESP. p. 91-107, 2003

KURTI, R. Steven; KURTI, Debby L.; FLEMING, Laura. The philosophy of educational makerspaces: Part 1 of making an educational makerspace. Teacher Librarian, Bowie, MD, v. 41, n. 5, p. 8-11, 2014. Disponível em: <http://www. teacherlibrarian.com/2014/06/18/educational-makerspaces>. Acesso em: 2 jun. 2021.

LALLEMENT, M. Travail: l'âge du faire? Sciences Humaines, n.266, 2015.

LÉVY, P. Cibercultura. São Paulo: Editora 34, 1999.

MARTINEZ, Sylvia L.; STAGER, Gary. Invent to learn: making, tinkering, and engineering in the classroom. Santa Barbara: Constructing Modern Knowledge Press, 2013.

MERCADO, L. P. L. Novas tecnologias na educação: reflexões sobre a prática. Maceió: EDUFAL, 2002.

MONTESSORI, Maria. Spontaneous activity in education. New York: Schocken Books, 1965.

MOURA, Eliton Meireles de. Formação docente e educação maker: o desafio do desenvolvimento das competências. Orientadora: Belmira Amélia de Barros Oliveira. 2019. Tese (Doutorado em Educação) - Faculdade de Educação, Universidade de São Paulo, São Paulo, 2019. Disponível em: doi:10.11606/T.48.2020.tde-03032020-171456. Acesso em: 14 jun. 2021.

NAÇÕES UNIDAS. Disponível em: <https://brasil.un.org/pt-br/sdgs>. Acesso em: 27 jun. 2021. 
OCDE. Preparing our youth for an inclusive and sustainable world - The OECD PISA global competence framework. OCDE, 2018. Disponível em <https://www.oecd.org/education/Global-competency-for-an-inclusive-world. pdf>; Acesso em: 15 mar. 2021.

OLIVEIRA, M. K. Vygotsky: aprendizado e desenvolvimento um processo sócio-histórico. São Paulo: Scipione, 2003.

OLIVEIRA, Dalila de Andrade. Gestão democrática da educação: desafios contemporâneos. 7. ed. Petrópolis, RJ. Editora Vozes. 2007.

PALFREY, J. Nascidos na era digital: entendendo a primeira geração de nativos digitais. Porto Alegre: Artmed, 2011.

PAPERT, Seymour. Mindstorms: children, Computer and Powerful Ideas. New York: Basic Books.1993.

Constructionism: a new opportunity for elementary science education. Proposta para a National Science Foundation, Massachusetts Institute of Technology, Media Laboratory, Epistemology and Learning Group, Cambridge MA, 1986.

Situating constructionism. In: HAREL, Idit; PAPERT, Seymour (ed.). Constructionism. Norwood NJ: Ablex, 1991, p. 1-11. Disponível em: <http://www.papert.org/articles/SituatingConstructionism.html>. Acesso em: 24 jun. 2021.

RESNICK, Mitchel. Lifelong Kindergarten: cultivating creativity through projects, passion, peers and play. Cambridge: MIT Press, 2017.

SANDHOLTZ, J. H.; RINGSTAFF, C.; DWYER, D. C. Ensinando com tecnologia: criando salas de aula centradas nos alunos. Porto Alegre: Artes Médicas, 1997.

SHIROISHI, Yoshihiro; UCHIYAMA, Kunio; SUZUKI, Norihiro. "Society 5.0: For Human Security and Well-Being," in: Computer, v. 51, n. 7, pp. 91-95, July 2018, doi: 10.1109/MC.2018.3011041.

SOSTER, Tatiana. Revelando as essências da educação maker: percepções das teorias e das práticas. 2018. 175 f. Tese (Doutorado em Educação: Currículo) - Programa de Estudos Pós-Graduados em Educação: Currículo, Pontifícia Universidade Católica de São Paulo, São Paulo, 2018.

SOSTER, Tatiana. Educação maker emancipatória. Tecnologias, sociedade e conhecimento, Campinas, SP, v. 6 , n. 2, p. 49-60, 2019. DOI: 10.20396/tsc.v6i2.14509. Disponível em: <https://econtents.bc.unicamp.br/inpec/index. php/tsc/article/view/14509>. Acesso em: 7 jul. 2021.

SOSTER; Tatiana; FUHRMANN, Tamar; CAMPOS, Fabio. Mapping Assessment Practices in School Makerspaces. In: FABLEAN ASIA 2020 - Constructive Diversity: Role of maker education in building diverse learning environment across cultures. Bangkok, Thailand. Proceedings [...]. Suksapattana Foundation, 2020. p. 25-29.

TEDESCO, J. C. O novo pacto educativo: educação, competitividade e cidadania na sociedade moderna. São Paulo: Ática, 1998. 
TURKLE, Sherry; PAPERT, Seymour. Epistemological Pluralism and the Revaluation of the Concrets. In: HAREL, Idit; PAPERT, Seymour. (EDS.). Constructionism: research reports and essays, 1985-1990. New Jersey: Ablex Pub. Corp, 1991. p. 161-192.

UNESCO. What is global citizenship education? Disponível em: <https://en.unesco.org/themes/gced/definition>. Acesso em: 27 jun. 2021.

VEIGA, I. P. A. Repensando a didática do ensino. Campinas, SP: Papirus, 1993. 